\title{
ANALYSIS OF WOLLONGONG CITY COUNCIL USING 7S'S OF GALLIERS AND SUTHERLAND METHODS
}

\author{
Indra Gamayanto \\ Information Systems Department, Faculty of Computer Science, Dian Nuswantoro University \\ Jln. Imam Bonjol No. 205-207, Semarang 50131, Indonesia \\ Indra.gamayanto@dsn.dinus.ac.id
}

Received: $21^{\text {st }}$ September 2017/ Revised: $23^{\text {rd }}$ October 2017/ Accepted: $24^{\text {th }}$ October 2017

\begin{abstract}
The research analyzed website of Wollongong City Council (WCC) and all the plans done by the WCC. It also showed details an Information Systems (IS) strategic plan for WCC. Although the WCC already had an integrated system, there were several key issues. The framework used to devise IS plan was seven stages (7S) of Gallier and Sutherland (G\&S). The approach assisted WCC in locating the current stage of its Information Technology (IT) maturity. From the analysis, it finds that IT currently is within stages 4 and stage 5 in seven stages. The final result will be the framework of the design as recommendations to the WCC.
\end{abstract}

Keywords: Wollongong City Council (WCC), the 7S's of Galliers \& Sutherland, IS strategic planning, IT maturity

\section{INTRODUCTION}

This research aimed to provide Wollongong City Council (WCC) with an Information Systems Strategic Plan (ISSP). Marabelli and Galliers (2017) stated that strategy was a cross-disciplinary topic in business-related disciplines such as management, marketing, economics and Information System (IS). This includes contributions from such eminent scholars as Henry Mintzberg (1979) and Michael Porter (1991), as well as practitioners such as Bruce Henderson as the Founder of the Boston Consulting Group and initiator of the 'strategic consultants' idea. Furthermore, strategizing through Information Technology (IT) has been a 'hot' topic and a major concern over four decades. IS strategizing provides a shared understanding across the organization to guide subsequent IT investment and deployment decisions of recalling earl's organizational view of IS strategy and reflecting the ongoing assessment of business needs to promote the ability to innovate. As a result, the dynamic process of strategizing contrasts with the planned strategy and its execution. It acknowledges that aspects of the actual strategy are emergent. This implies that tensions exist between existing plans, ideas and resources, and exploring new and emerging means to achieve organizational objectives (Marabelli \& Galliers, 2017).

ISSP requires organizations to define their business goals and plans, and determine IT strategies that optimize achieving business objectives. It is broader and more corporately accountable than other forms of IS planning. Contextually the characteristics that define ISSP include scope (which is broad); perspective (which planning position is at the highest organizational levels); timeframe (which is longer as initiatives relating to significant organizational change); and level of abstraction (as ISSP relates to more conceptual planning than to practical initiatives). Therefore, ISSP involves formalizing the best strategic business IS/ IT planning approaches for a particular organization; a strategic plan for implementation; how to champion the process; the size of commitment regarding people, financial and other resources; and a review processes. It can help WCC in achieving its strategic and corporate goals. The ISSP provides a framework that WCC can use to accomplish its Information Technology (IT) development, which is the highest state of IT maturity.

One of the approaches that can be used is seven stages (7S) of Gallier and Sutherland (G\&S) (Galliers \& Leidner, 2003). According to Peppard, Galliers, and Thorogood (2014), the first stage (Ad Hocracy) matches Nomology's physical or survey stage. The emphasis is on the physical presence of IT. The second stage (Starting the Foundations) corresponds to the political or study stage. IT starts to have impact on the organization. Moreover, IT people begin to look for recognition and influence. The third stage (Centralized Dictatorship) has mainly been won. This corresponds to the economic stage. The argument is about the definition of end-user requirements such as what would be best for the organization, which it would do best, and how it should be done.

The fourth stage (Democratic Dialectic and Cooperation) corresponds to three development stages. There are the social, cultural, and emotional levels. The fifth stage (Entrepreneurial Opportunity) corresponds mainly to the artistic level/construction stage, but also partly to the religious level/delivery stage. The entrepreneurial and individualistic product behaves like an artist and creatively constructs a new business opportunity. The sixth stage (Integrated Harmonious Relationships) matches with some extent of the religious and mainly the mystical level where everything works together as it should in harmony (Peppard, Galliers, \& Thorogood, 2014).

Although the approach is good, it has several weaknesses. The issues compromise the applicability of the ISSP for WCC. These issues and criticisms are described in detail in this research. This research provides an in-depth analysis of the WCC organization from what they have done and what they will do in the future. The report of corporate plans and other reports which can be downloaded on the WCC website is analyzed and collected.

\section{METHODS}

This research uses the $7 \mathrm{~S}$ method of G\&S. This method is to find out to what extent an organization is progressing in a better direction. There is a method like Cobit 5.0 , but the $7 \mathrm{~S}$ of G\&S is a very useful method of 
helping organizations know the maturity level of IT. The data obtained from the WCC research website such as the annual plan owned by the WCC. The data explains that the WCC still needs a more innovative development, especially regarding the issue of how WCC can create a system that can be more integrated so that it can accelerate its service to the community of Wollongong city, Australia.

The approach taken by G\&S will be used to derive the ISSP. The first step will be to describe WCC's current stage of IT maturity in terms of Strategy, Structure, Systems, Staff, Style, Skills and Superordinate Goals (7S). A summary of the meanings of the 7S is available in Table 1. By using the $7 \mathrm{~S}$ model, the researcher first needs to identify what stage WCC is at before strategies can be suggested at the final stage. The second step is to suggest steps/strategies (via an ISSP) and allow WCC to progress into the final stage of the G\&S model, which is stage 6 or Integrated harmonious relationships. A description of the six stages of IT maturity of the G\&S approach is in Table 2.

Table 1 The $7 \mathrm{~S}$ of G\&S

\begin{tabular}{|c|c|}
\hline Variable & Description \\
\hline Strategy & $\begin{array}{l}\text { Plan or course of action leading to the al- } \\
\text { location of a firm's scarce resources to reach } \\
\text { identified goals. }\end{array}$ \\
\hline Structure & $\begin{array}{l}\text { Characterization of the organization chart } \\
\text { (i.e., functional, decentralized) }\end{array}$ \\
\hline Systems & $\begin{array}{l}\text { Procedural reports and routine processes } \\
\text { such as meeting formats }\end{array}$ \\
\hline Staff & $\begin{array}{l}\text { Demographic description of important per- } \\
\text { sonnel categories within the firm (i.e., engi- } \\
\text { neers, entrepreneurs, MBAs). The staff does } \\
\text { not mean in line-staff terms. }\end{array}$ \\
\hline Style & $\begin{array}{l}\text { Characterization of how key managers be- } \\
\text { have in achieving the organization's goals, } \\
\text { also the cultural style of the organization. }\end{array}$ \\
\hline Skills & $\begin{array}{l}\text { Distinctive capabilities of key personnel or } \\
\text { the firm as a whole }\end{array}$ \\
\hline $\begin{array}{l}\text { Superordinate } \\
\text { Goals }\end{array}$ & $\begin{array}{l}\text { The significant meanings or guiding con- } \\
\text { cepts that an organization imbues in its } \\
\text { members. Superordinate goals can also be } \\
\text { described as the shared values or culture of } \\
\text { the organization. }\end{array}$ \\
\hline
\end{tabular}

(Source: Galliers \& Leidner, 2003)

Table 2 Six Stages of IT Growth of G\&S

\begin{tabular}{|c|c|}
\hline $\begin{array}{c}\text { Stage } \\
\text { Number }\end{array}$ & Description \\
\hline 1 & $\begin{array}{l}\text { Ad Hocracy: } \\
\text { Uncontrolled ad hoc approach to the use of I.T. }\end{array}$ \\
\hline 2 & $\begin{array}{l}\text { Starting the Foundations: } \\
\text { Beginning of ascendancy of IT in the organization. }\end{array}$ \\
\hline 3 & $\begin{array}{l}\text { Centralised Dictatorship: } \\
\text { The beginning of strong management control. }\end{array}$ \\
\hline 4 & $\begin{array}{l}\text { Democratic Dialectics and Dooperation: } \\
\text { State of disarray with little coordination between } \\
\text { IS department and user departments. }\end{array}$ \\
\hline 5 & $\begin{array}{l}\text { Entrepreneurial Opportunity: } \\
\text { Strategic benefits beginning to emerge }\end{array}$ \\
\hline 6 & $\begin{array}{l}\text { Integrated Harmonious Relationships: } \\
\text { Sophisticated use of IT and harmonious working } \\
\text { relationship between IT personnel and other staff } \\
\text { in the organization. }\end{array}$ \\
\hline
\end{tabular}

(Source: Galliers \& Leidner, 2003)
From Table 1 and 2, it can be seen that there are seven important elements in this method. There are Strategy, Structure, Systems, Staff, Style, Skills, and Superordinate Goals. Then, there are also six levels as a measure of maturity. This greatly helps an organization to know their weaknesses and strengths so that it can be improved and innovated to become an effective and efficient business process and IS/IT strategic plan. The process in this research is in Figure 1.

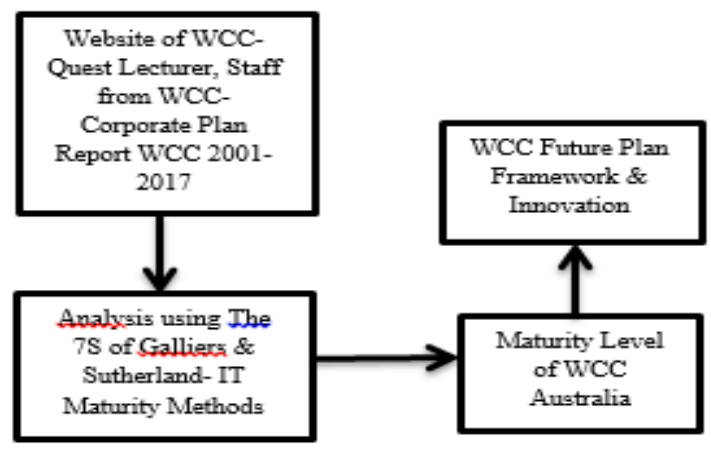

Figure 1 Process of 7S in WCC

The process is to look at the contents of the report provided by the WCC. This research contains the entire plan and what has been done by the WCC. Next, the result of the quest lecturer-staff WCC is summarized into single unified information. It can be united and analyzed along with the report contained in the $\mathrm{WCC}$ website. The final stage is to analyze the entire information using $7 \mathrm{~S}$ method and to produce WCC Future Plan Framework \& Innovation. It is the result of the design as a recommendation to the WCC in the future in making Wollongong City as the best city in Australia or as examples for other cities around the world.

\section{RESULTS AND DISCUSSIONS}

In the analysis of Strategy, the changes that the WCC has gone through over the years are taken into consideration such as the internal and external factors affecting its operations. People can see the way that IT has shaped its decision-making process. The proof is the sharp increase in the IT budget. The notes provided by WCC annual report reflected that it had a very strong dependency on IT. Technology is utilized to assist in the effective cost of delivering the services and ensure that the expectations of its customers are met. The creation of Information Systems Policy Group (ISPG) strengthens this system. The role of the group comprises of various functions such as policy determination for the present and future directions by prioritizing IT projects and conducting constant reviews for performance monitoring. The IT factor acts as a catalyst in making sure that the IT strategy has alignment with the corporate goals of WCC, and how it can enhance WCC prospects in creating a strategy to gain a competitive strategic advantage. It must be known that the constant cost-effectiveness factor may have a negative impact while designing some future strategies (Marabelli \& Galliers, 2017).

Most of the projects follow an approval path based on these criteria, rather than looking at the long-term benefits that may be undermined by using the procedure. Based on 
these details, The IT in WCC seems to be between the fourth and the fifth stage in terms of its strategy. It has achieved the fourth stage and is somewhere in the fifth stage, but not all the steps are met yet (Amrollahi, Ghapanchi, \& TalaeiKhoei, 2013).

According to the model, the last stage is the integrated harmonious relationships. The next goal of WCC is to achieve that stage. To reach that stage, the following issues should be addressed. First, the strategy criteria are focused solely on one aspect, which is customer satisfaction. Too much emphasis on one area and ignoring the other areas can provide long-term strategic potholes. It is arguable that if the key mission of WCC is to serve people (customers), this is why this approach is wrong. Strategies cannot only be dependent on one aspect. Different areas of the organization have to be looked too such as competition, organizational structure, and behavior. Moreover, WCC has to look at its profit level as well which supports its operations and allows it to gain competitive advantage. Second, although WCC corporately is quite satisfied with its IT departments' performance and the role in enhancing its image and overall performance. The key issues like software outsourcing, equipment, and system leasing have to be taken into consideration more rigorously while designing future strategies (Hussin, Othman, \& Jamaludin, 2017; Khan, 2016). Constant reassessment of both the internal and external factors must be done by WCC by monitoring and employing performance measuring techniques. For WCC to fully benefit from IT implementation and reach stage 6 , it has to employ the combination of business-led and IT-led approaches. This will help WCC to successfully reach that stage which will not be possible unless the issues discussed are addressed when formulating any future strategies.

For the analysis of the Structure, WCC's management structure is comprised of both executive and senior management level. The executive management group is responsible for policy, strategic direction, and overall management. Meanwhile, the senior management group handles the tactical management and day-to-day operations. Like most commonly reflected in most of the public service organizations, the structure employs a top-down planning approach. The main reason for such an approach is to keep the central command to make sure that most of the decisions are controlled more effectively. By looking at the structure, it may seem that it is very centralized, but there is a degree of flexible and visible decentralization. The three directors reporting to the general manager have their share of responsibilities and operational manager report to them. All of them who are working in different departments report to different people, but they still have their duties to perform. The IT department is concerned ISPG about the peak corporate body for IT decision-making (Omar et al., 2014; Buntin et al., 2011). Their job pertains the steering committee, and the structure of the membership body include a member representing each of department. This sort of structure is reflected in stage 4 of the G\&S model where by integration and other changes in the organization take place. As mentioned by the WCC spokesperson, the council employs Business Analysts in IT and other divisions. This pushes the WCC towards stage 5 of the model. Thus, based on the information provided, they have achieved the stage 4 of the model and have taken the first step towards the stage 5. WCC's Structure in strategic plan has reached stage 6 to move from the current stage of maturity which is integrated harmonious relationships. WCC has to consider and focus on the following areas. It is high that the WCC will completely overhaul its organizational structure hierarchy towards a more flat and decentralized one. Normally no government organization operates in this manner. Still, what can be achieved via a greater individualistic approach may lead to harmony between the different divisions, which will lead them to stage 6 . The IT department's structure follows a very strict approach as far as investment or project approvals are a concern.

This is to ensure that unnecessary costs are controlled since they need to ensure that cost-effectiveness is realized. As the decision-making process is concerned, the structure involved by the ISPG group is a commendable one and should be further enhanced. By involving members who are representing different departments, the improved interactive plans can evolve. Also, a greater organizational understanding is achieved by discussing the issues of their respective department with each other. This sort of collaboration can result in determining policies which will lead to future directions with a common goal-oriented approach. So far, WCC has mostly used IT to support the systems that are in place and to make sure that everything is going smooth. This approach has to be changed by WCC. This coalition has to be further enhanced by changing the overall corporate view, whereby IT will play a more significant role and emphasis more on the alignment of the business objective with the IT objectives. IT should be considered more than just supporting the departments. When the key business objectives are aligned with those of IT, the result is a more cohesive approach, which results in a development of better IS/IT products and strategies.

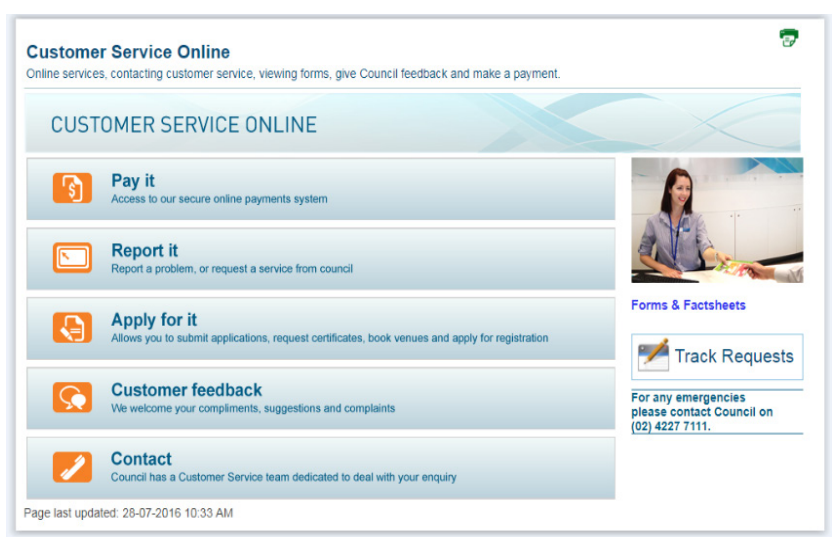

Figure 2 WCC \& Systems

(Example of Customer Service Online)

In Figure 2, WCC has a useful online customer to help residents in the city of Wollongong to make payments, report problems online, registrate, complain and directly contact customer service. This greatly helps IT systems at WCC run very effectively and efficiently. For analysis of the Systems, IS is composed by the business goals to be supported by the system (the purpose), the people that run and use the system, the procedures needed for the system to be successfully integrated into the organization's flow of work, the information being processed and communicated by the system, and the information and communication technologies used to implement the system (Wilkin \& Cerpa, 2012).

WCC is one of the government organizations that the use of IT to increase the capability of the systems in the organization. The purpose of this part is to analyze the systems and staff at WCC. The research analyzes which 
stage that WCC has for the systems and staff. Then, it gives a solution how WCC gain the next stage to get a competitive advantage on systems in the future. There are some stages for analyzing the systems at WCC. Stage 1 defines unconnected, operational, multiple manuals of Ad hoc and uncoordinated, concentration in financial systems, and little maintenance of IS. Stage 2 defines many applications, gaps, overlapping systems, centralized, operational, mainly financial systems, unsatisfied areas, a large backlog, and heavy maintenance load. Stage 3 is the most centralized, uncontrolled end-user computing, most major business activities covered, and database systems (Lin et al., 2007).

WCC's stage in System is between stage 4 and 5 . WCC identifies that some systems need to be revised step by step to gain better systems in the organization. The systems are Land Information Systems, Financial Management Information Systems, Library Systems upgrade, Electronic Document Management, and upgrade of Local Area Network. Furthermore, the current methodology implemented is a mixture of centralized and decentralized. The applications are owned by the client division and supported by that division. The infrastructure management and planning and procurement are centralized. WCC is in the middle of the systems, it means between stage 4 and 5 that WCC has a decentralized approach with some controls, but mostly it lacks co-ordination. WCC also has decentralized systems, but it is central control and coordination.

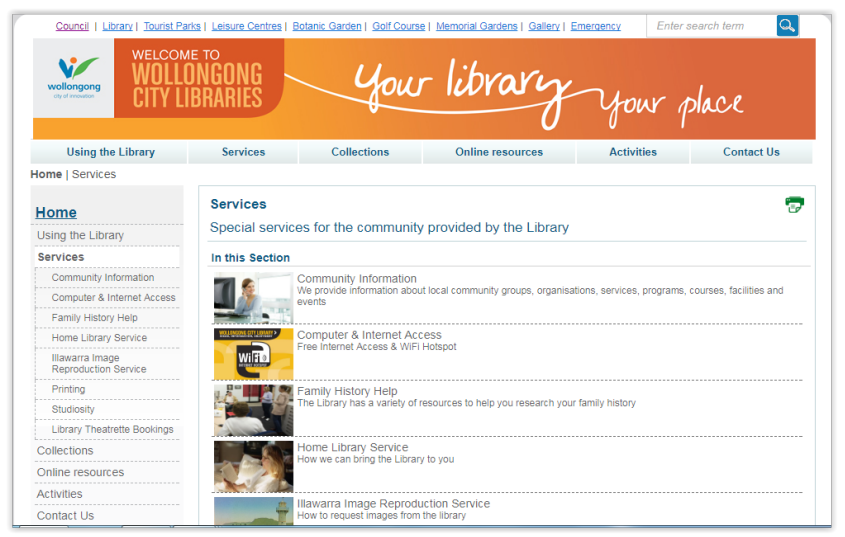

Figure 3 Library Systems in WCC

In Figure 3, funding for the library systems is split between IT Capital and library operating costs. New and replaced equipment is funded from IT Capital allocations. Meanwhile, the on going support is predominantly funded from library operating costs for microcomputer-based library systems by complying with corporate standards as a home from IT operational funds (Bradbery, 2017a). To reach stage 6 , WCC does not need to split the systems in the library, but WCC has to make the funding of the library systems central. This means that if $\mathrm{WCC}$ wants to gain a better system, WCC has to centralize the systems. WCC does not need to split the funding. The funding of library systems has to centralize all in the one systems. Therefore, WCC can increase the systems in the library better than before. WCC has recently upgraded to Microsoft XP for its desktops. WCC is currently in phase 2 of the implementation of a human resource management system (Aurion). Moreover, the new applications currently implemented are finance, technology and finance applications, and the pathways of GEAC for the Land Information System. Then, the integrating of the systems is good. The new applications are specifically specified with interface and integration points as the part of the tender contract. Next, WCC has a plan for stand-alone systems. The plan tries and picks up the possible stand-alone system. This process formes part of the decision as to what is within the project scope of new applications and what was outside the scope. The researcher identifies that there is a lack of systems in the new systems. For instance, WCC changes the corporate systems, file and print servers, Internet/Intranet, GIS, desktop systems, desktop application software, and systems development. To reach stage $6, \mathrm{WCC}$ has to base on one product. It seems that WCC has made many changes in the systems of IT application. Therefore, it increases the budget and decreases the effectiveness of the systems. Although the new application and other systems can run very well, WCC has to consider the flow of the financial systems. As a result, WCC has to centralize the systems and especially focuses on external-internal data integration development, Inter-organizational systems, and New IS based products. WCC also has to increase the customer service in the whole systems such as library systems. However, it must also focus on customer satisfaction so that WCC can gain a competitive advantage on systems in the future. WCC has to identify and compare with other organizations to get a better system and determine whether these systems can be implemented in WCC or not.

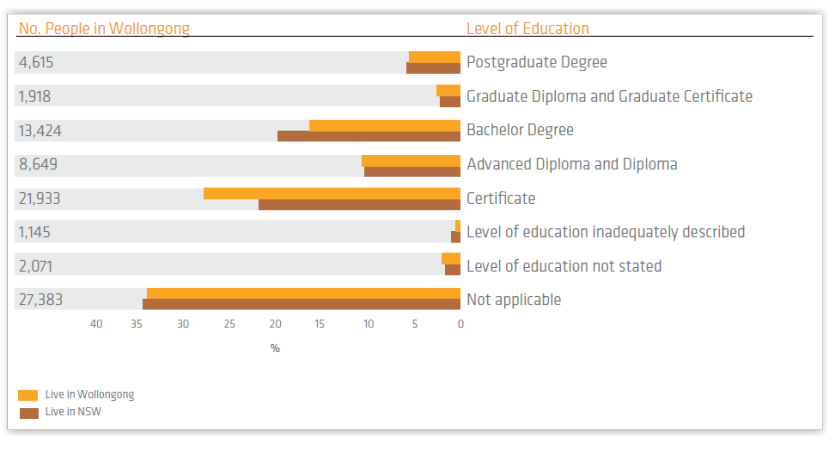

Figure 4 Level of Education in WCC (Source: Bradbery, 2013)

It is shown in Figure 4 that the staff at WCC has an excellent and reliable level of education in the face of globalization. Staff with varying expertise will be able to enhance teamwork so that the WCC can develop its organization for the better in the future. Next, for analysis of Staff, there are some stages of analyzing the staff at WCC. Stage 1 defines programmers/contractors. Stage 2 defines systems analysts, DP Manager. Stage 3 is IS planner, IS Manager, database administrator, data administrator, and data analysts. Moreover for the staff, WCC does employ a business analyst based in the divisions and the IT group. All of the IT staff are all degree qualified. WCC has all varieties of degrees such as B Math, B Com (Bus Sys), B Info Tech, M Com, MBA, and B Com. WCC is in between stage 4 and 5 because WCC has only a business analysts and manager in the staff structure. WCC does not have Chief Information Officer (CIO) in the staff structure. WCC has a manager administration and IT, senior coordinator IT (Pratikna \& Gamayanto, 2017). To reach stage 6, WCC has to consider the staff structure. For instance, WCC has a manager of 
finance, administration and IT that manage the financial system, administration system, and IT system. Also, if a manager is managing three divisions, the effectiveness will not run very well. IT manager should separate from other divisions to increase the performance and capability of organization or staffs function.

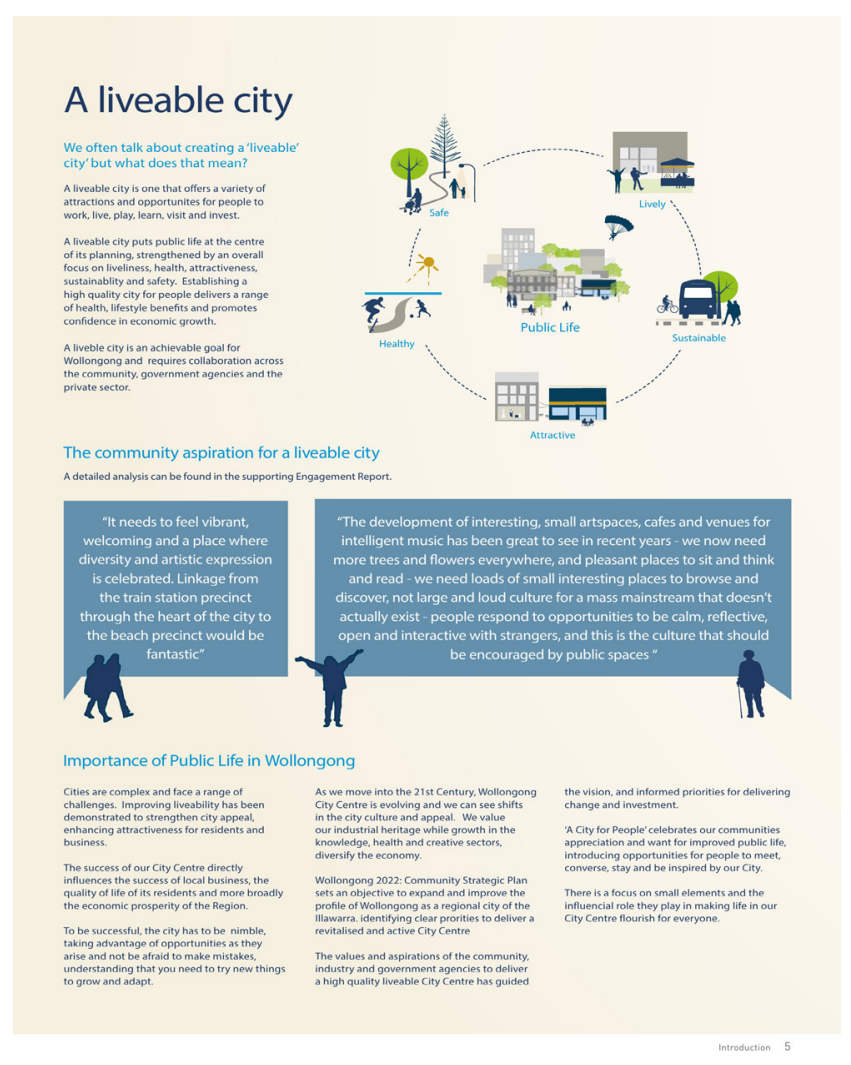

Figure 5 WCC as City of Innovation and Style (Source: Gehl, 2014)

WCC is a city that has a high innovation and continues to grow. Figure 5 is an innovation circle conducted by the WCC in the face of today's global competition. The city can continue to benefit Australia and become one of the best cities.

For Style, IT is currently implemented with consideration as to how it affects $\mathrm{WCC}$ in its processes and human resources. WCC's IT staffs are technically competent. They seek the involvement of users in the development of new systems. They have a good rapport with WCC's staff and treat them as a partner. Users cannot simply do as they please regarding IT acquisition and IS development. The activities must be coordinated with IT department. The IT manager works in conjunction with the rest of the organization for its overall benefit. WCC has an ISPG, which addresses the implementation of IS to obtain strategic advantage for WCC. WCC follows a rigid template for the approval of its IT projects where the project is approved, and the monetary benefit is greater than the monetary cost (Bradbery, 2017b). Therefore, it can be concluded that WCC currently resides between stages 4 and 5 of S\&G model in terms of its Style. WCC has reached stage 4 and satisfy some of the requirements of stage 5 but not all of them.

To reach stage 5, WCC needs to broaden its approval method of IT projects. They currently approve projects on economic cost-benefit ratio terms, but they also need to carefully look at those projects whereby the monetary cost is greater than the monetary benefits. It can still be approved because some systems have non-quantifiable (or intangible) benefits which can assist WCC to achieve its strategic goals. For example, employee and ratepayers' morale is an intangible benefit. Projects which address morale (such as improved IT service to employees and community-based functions) assist WCC in attaining strategic benefits (such as reduced staff turnover, and retention of ratepayers in the WCC region), which in the long run will result in improved economic benefits for WCC. WCC should employ product champions to achieve this. Typically, a champion pushes the conception through the necessary procedures to get it off the ground and to work. They will need to liaise with WCC's more powerful members (upper management) to ensure that they are implemented and avoid the risk of it being stalled in mid-development. Then, to reach stage 6 , the organization needs to be a unit with IT by working together to make and keep the organization successful. Currently, this is not achievable because WCC's outsources its software development for third parties. Thus, WCC needs to adopt this on an in-house basis to reach this stage.

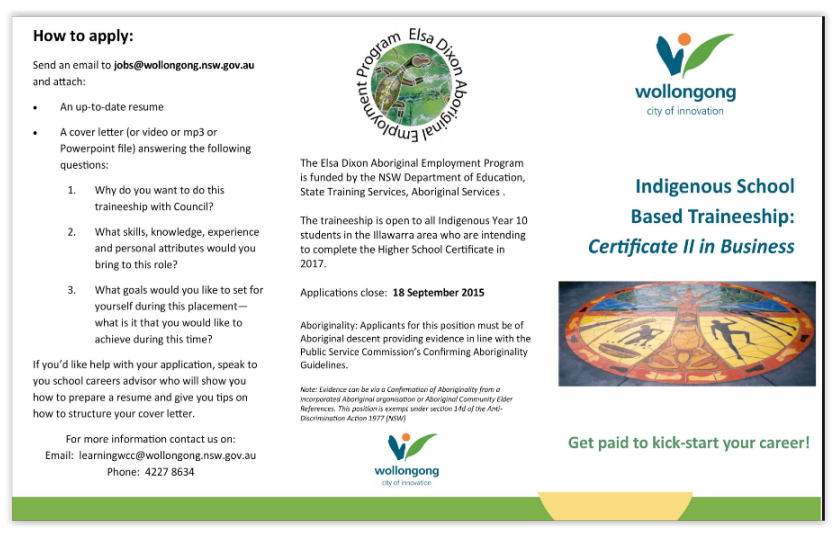

Figure 6 WCC-Skills-Working

It is shown in Figure 6, WCC opens employment opportunities to aborigines and this is an excellent opportunity to produce qualified human resources (Land, 2016).

For Skills, the technical skills of the IT personnel are very good. This is primarily because WCC assesses the key or required competencies of the candidates when it hires its personnel. Once employed by WCC, the skills that are developed by the IT personnel are shared amongst each other. WCC provides an ideal environment for its staff to acquire skills, in the form of job training as well as the deployment of various projects. As long as staffs are proactive in the enrichment of their skills, WCC provides the platform and framework in which to learn. Computers and computer applications are relatively modern, and WCC always reviews these to keep abreast with the latest technologies. IT staff also has the required skills associated with building and installing complete systems for the organization.

WCC follows a system development methodology and adopts project management guidelines to help coordinate this. The methodology comprises of a series of the template, which the analysts fill in section per section. 
It includes common items such as a project description, key stakeholders, scope of the project, and estimated costs and benefits. The business knowledge and skills of IT staff are rated as good. They proactively go to meetings with the business to stay abreast of their current knowledge and to also pick up on the future trends and direction of the business. In return, the users gain insight into IT related issues and its future direction within the organization. Thus, a greater integration and understanding between the units is evident. The IT group is viewed as an integral part of a successful operation of the organization. Both top management and end users are happy with the service provided by the IT group and view them as knowledgeable. The IT staffs have strong business, entrepreneurial and marketing skills, with degrees such as Bachelor of Commerce, Masters in Commerce, and an MBA. However, IT personnel does not have board level knowledge as well as for senior manager (Gehl, 2014). Therefore, WCC currently has reached stage 5 of the G\&S model in terms of its Skills. WCC's skills-strategic plan to reach stage 6 . To move from WCC's current stage of maturity in terms of its skills to that of stage 6 of integrated harmonious relationships, WCC needs to address the skills of its IT personnel. They need to acquire the equivalent skills to that member of WCC. Attending the meetings and undertaking the same educational qualifications of such personnel are the way to achieve this. A similar undertaking is required for WCC's senior managers. A closer integration with WCC strategic planning division is also required.

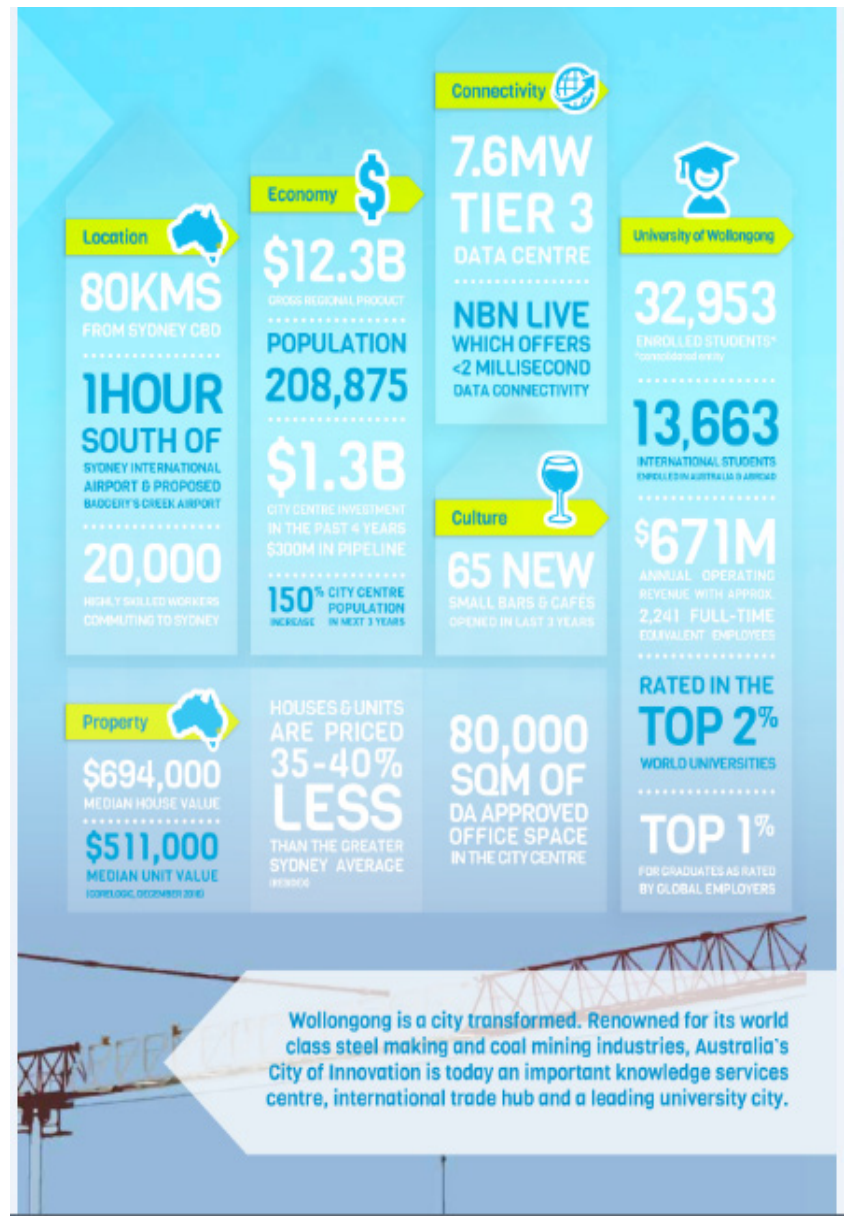

Figure 7 Data of Wollongong City (Source: Ward, 2017)
It is shown in Figure 7. The data presented is an improvement in the city of Wollongong. One of the best in the city is the University of Wollongong. It is one of the universities that produce a lot of human resources with high quality. Thus, it provides many benefits to Australia as well society in general (Ward, 2017).

In Superordinate Goals, WCC has a clear conception of what is happening in the IT area, inclusive of their use, responsibilities, and goals. The examples of shared superordinate goals within IT area include customer support and support of IS corporate.

In Figure 8, it is an economic growth data owned by the WCC and one of the progress reports of the city. Furthermore, the touris level also increases to provide income to the city of Wollongong (Bradbery, 2013).

All implementations of IT projects are required to present a business case with their proposals. A part of the business case is a six monthly review. This review ensures there is no return on investment of the project. Then a decision is made whether to withdraw or recoup funding. Conversely, the review helps to ensure an accrued return on investment. WCC has a set of common goals in which all areas of WCC work. These corporate goals reach across divisional and corporate plan boundaries. These goals provide guidance in the activities of all staff within WCC. Some of these include customer satisfaction, environmental, and economic activity (Gamayanto, 2004). All areas in the organization gain an understanding of other areas via cross-

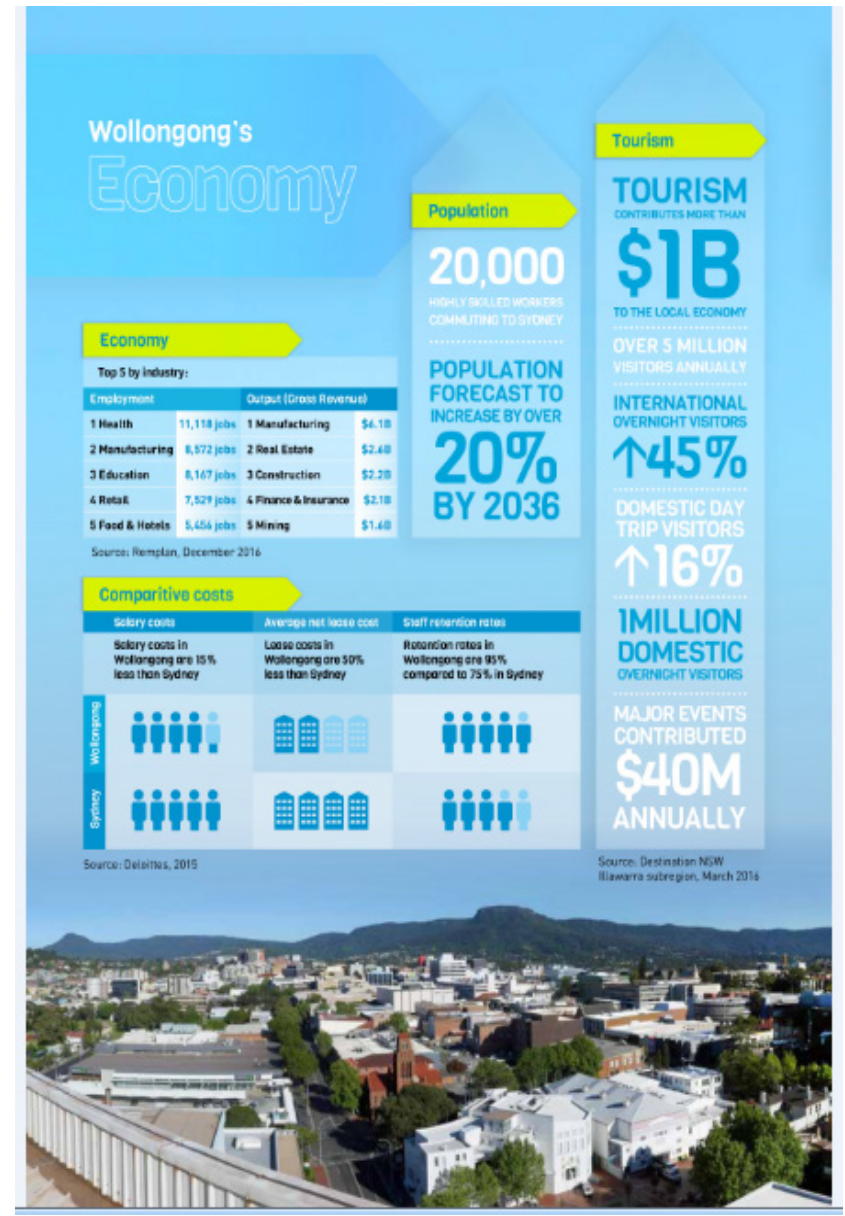

Figure 8 Economy Future in Wollongong City (Source: Bradbery, 2013) 
attendance of meetings as well as higher-level meetings to which members of all areas are invited. From this, there exists an entrepreneurial attitude within WCC, with the ideas of obtaining strategic advantage is encouraged. Such opportunities are available due to the cross-organizational harmonies that currently exist within WCC. WCC still forms strong alliances with those external factors to WCC such as customers and suppliers. Therefore, it can be said that WCC has reached stage 5 of the S\&G model in terms of Superordinate Goals.

To move from WCC's current stage of maturity regarding its Superordinate Goals to stage 6 of integrated harmonious relationships, WCC needs to address several things. Although WCC has good intra-organizational relationships, the improved interactive planning, and greater interdependent teamwork can instill a greater sense of shared values amongst its people. A collaborative initiative can result in improved IS strategic in products. WCC is only in its infancy regarding forming strategic alliances with those external factors to WCC. There have been several attempts in forming alliances to gain economies with the costs of implementing council applications. For example, five Sydney councils pool their resources to engage a contractor to bring an integrated system for the councils. This can assist WCC in securing a customized integrated system. Many other potential opportunities exist with other councils which is closer in proximity to Sydney. They are yet explored by WCC and should adopt their strategic planning group. Since councils primarily have similar functions, there is the possibility that they can share similar information systems and customize them accordingly to WCC's needs. Although WCC has alliances with its suppliers, it is primarily on a contract basis. It can be strengthened by adopting these suppliers as an in-house basis such as with WCC's software development contractors.

In addition, WCC needs to strengthen its alliances with its customers (ratepayers) by improving the planning and communication. For example, there is customer dissatisfaction with Lawrence Hargraves road. The cars in the road are blocked when the rainfall rises to 35 millimeters. Although WCC does this for the safety of its people, it should improve the communication to its people. It is because people need to take alternative and longer routes. If this is planned and coordinated better, the ratepayers can be less inconvenienced.

There are issues and criticisms in applying G\&S method. Developing a strategy in a newly emerging industry or business under revolutionary technological change is a daunting task. According to Porter (Gamayanto, 2004), the dynamic ways change each day. It is almost impossible to derive something based on a decade ago. One of the major hurdles faced while doing this research is to apply the G\&S model which originated in the late 1980's. This is a decade and a half years old. Then, IT industry has taken a 360-degree turn. A lot of the terminologies and assumptions which can be applied are obsolete now. Some of these terms are mentioned in stage 4 of the model such as Data processing (DP) departments and DP managers have been discarded. This provides a bit of a dilemma for the person to apply the model to get the true picture because the responsibilities also change over time. The model seems to focus on the assumption that the organization reviewed is a typical private business organization. There are no alternatives provided if the enterprise is a public service body like WCC which is a non-profit organization. Other issues in WCC also come in to picture such as public pressures, political insecurities, and economic instabilities which have not been addressed.

In addition, the strategy formulation procedure of WCC is quite different to a normal business organization whose prime interest is to make as much profit as possible. The underlying motto of WCC is also profit making, but the applied model is very hard to assess this. As far as the structure goes, the organizational structure of the WCC is a typical government body. The model takes a broader approach by assuming that the enterprise in question is a business one. Also, the explanations provided in the model are too global and do not delve into specific details. Due to the nature of the details provided in the model, for both strategy and structure, the researcher finds WCC somewhere in the middle. This is because the model does not supply sufficient information to judge precisely what stage WCC can be in. If it is conducted by several different people, the results can produce extreme variation.

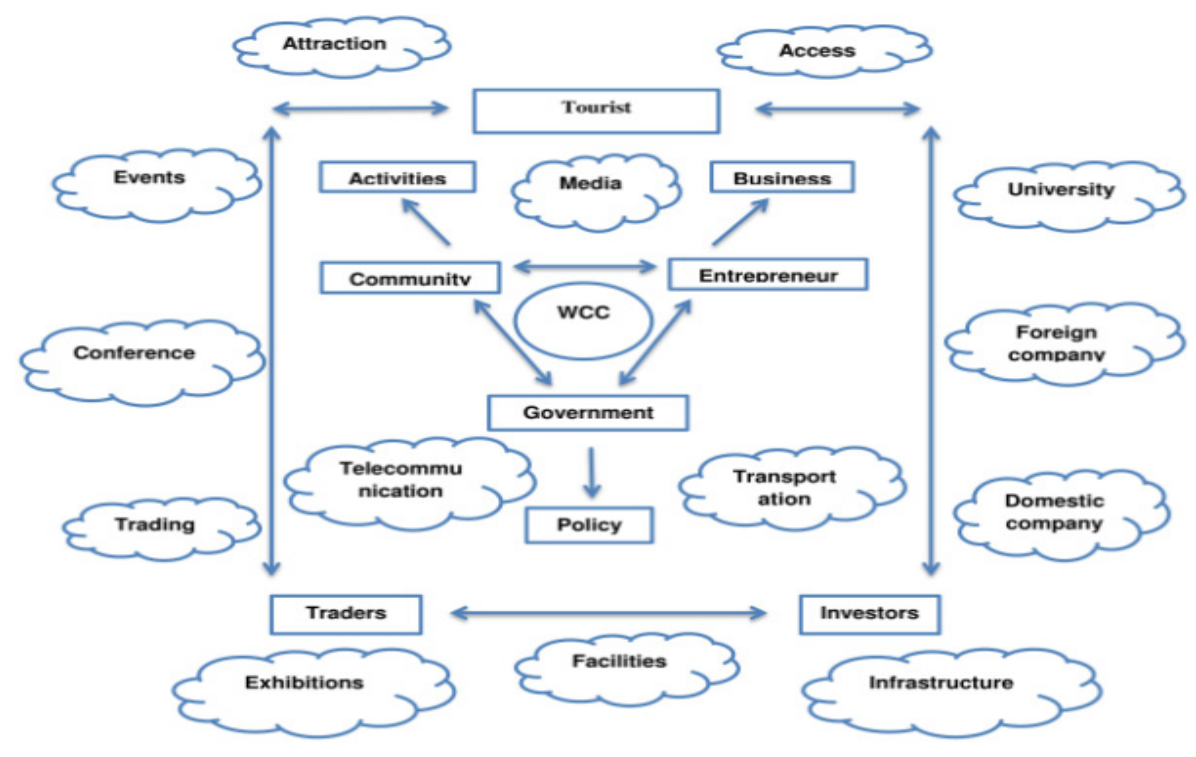

Figure 9 WCC Future Plan Frameworks and Innovation 
In Figure 9, a new framework for WCC is shown. The main function of the WCC future frameworks can give the WCC a big picture to have a roadmap for integrating everything and what will be done in the future. First, at the middle circle, there are the WCC and surrounded government, community (society), entrepreneurs. These things are inseparable from one another in government. The Australian government strongly supports Wollongong City through WCC as a media organization that submits important regulations made by the government. In the community, the WCC takes note of the existing community by facilitating all positive activities to have a tremendous impact on society. For example, it can be cultural growth. For the entrepreneur, WCC invites entrepreneurs to invest in Wollongong City and make progress in urban areas, facilities, and so on, so that people can work effectively and efficiently (Sanson, 2015; Alamri et al., 2016).

Then, there are three important sectors, telecommunications, media, and transport. In the telecommunications, telecommunication companies are built in several places. The sophistication of communications is developed continuously so people can communicate quickly. Furthermore, transport, which is an infrastructure, is essential. If the infrastructure is not built, there are ineffective and efficient impacts, such as goods becomes expensive. Meanwhile, the media has a role in communicating right things to the community, so that it forms transparent news by facts. The important point here is that infrastructure development can continue to be done, but it should remember the capabilities, and the welfare of the users, the community, and the maintenance because infrastructure development without considering the economic factors of society and the cost of maintenance will lead to chaos. The Australian government, WCC, and society undertake exceptional cooperation, in which the income derived from taxes provides great benefits and impacts to society. This is because it puts the human resources in the right position so that it can be managed properly. Then, Australian-WCC government has significant returns.

In the tourist, traders, and investor section, these profoundly affect the side of profits for the Australian-WCC government. Wollongong has very beautiful beaches, and some fabulous recreation parks, so the WCC does a massive overhaul to boost the tourism sector and bring benefits to the WCC. WCC is very smart in doing the cycle of improving the living standards of the community - returning to WCC WCC is working on and building up the living - improving facilities - back again to WCC (simple profitability cycle that has benefits for sides, government and society). This is done by WCC so that there is stability in the local government of Wollongong City.

The ease for investors and business people to invest is helped by WCC so that the level of investors increases and there is a huge economic impact change. If the security is not stable in an environment, it is useless and wastes time to convince investors to invest. It is because if someone builds something or invests in a place, and the place is uncomfortable or unsafe, it will be very difficult to convince investors. There are also many other sides which must be considered carefully. For example, education like the university is also an important thing that should not be ignored. With the establishment of the University of Wollongong, which is the best university, the standard of living of the community can increase as well. Many international students have come to Wollongong, and WCC realizes this very carefully. Therefore, one of the most important pillars of education should not be separated from its influence on the welfare of society. Furthermore, WCC facilitates local products in Wollongong City which are the main characteristics. Those innovative products created can also increase the employment sector. The absorption of good employment can increase the extraordinary productivity channels of people's life cycles. This impacts benefits not only Wollongong City but also cities not far from Wollongong. The cultural influences are so great in Wollongong, and these influences make a positive attitude to the behavior of the people. The community becomes more tolerant, understood each other, helped each other, and maintains the infrastructure/facilities that the WCC has built. Cultural change is possible if the old habit has been eroded to a minimum level. This principle is an understanding of cultural mix. It results in a competitive advantage for society and government. The WCC does this very well, so for people, there are many changes. These changes have an impact on the state. Therefore, the application of IT also needs to be built properly. Ignoring information technology can cause massive changes to the way people live. However, the WCC can apply IT, and its functions and benefits can create a smart economy that produces human technology positively.

\section{CONCLUSIONS}

WCC is currently quite advanced regarding its IT maturity. For all stages of $7 \mathrm{~S}$ of the G\&S model, WCC falls in stage 4 and stage 5 of the model or somewhere in between. The summarization is available in Table 3 .

The findings are crucial for WCC to advance from its current status of IT maturity to a status of integrated harmonious relationships (Stage 6 of the G\&S model). However, these findings should not be implemented without further assessment and consideration. This is because several issues and criticisms of the G\&S approach are found when compiling this research. Thus, it hinders the applicability of the recommendations and strategies proposed. Some of these issues include out-dated IT terminology, and it cannot be applied to modern IT methods. Then, the approach suits to private organizations, not government bodies better. The current stage of a firm is subjective, and it is open to criticism. Nevertheless, this research still provides a useful strategic plan for WCC to achieve its goals. Then, it provides a foundation for further analysis. The further analysis can be done by applying other models like Porter's model or Nolan's model. The application of this ISSP by WCC's IS and IT staff should continue to help WCC retain its strategic competitive advantage now and in the future.

Table 3 7S and IT Maturity Level

\begin{tabular}{cc}
\hline $\mathbf{7 S}$ & IT Maturity of WCC \\
\hline Strategy & Between stage 4 and 5 \\
Structure & Stage 4 \\
System & Between stage 4 and 5 \\
Staff & Between stage 4 and 5 \\
Style & Between stage 4 and 5 \\
Skills & Stage 5 \\
Superordinate Goals & Stage 5 \\
Summary: & WCC is in between stages 4 and 5 \\
& of the G\&S model \\
\hline
\end{tabular}




\section{REFERENCES}

Alamri, S., Almutiri, N., Ballahmar, H., \& Zafar, A. (2016). Strategic information system planning: A case study of a service delivery company. Iarjset, 3(5), 78-84.

Amrollahi, A., Ghapanchi, A. H., \& Talaei-Khoei, A. (2013). A systematic literature review on strategic information systems planning: Insights from the past decade. Pacific Asia Journal of the Association for Information Systems, 5(2), 39-66.

Bradbery, G. (2013). Economic development. Retrieved January $23^{\text {th }}, 2017$ from http://www.wollongong. nsw.gov.au/city/economicdevelopment/Pages/ default.aspx

Bradbery, G. (2017a). Annual plan 2017 - 2018. Retrieved January $30^{\text {th }}, 2017$ from http://www.wollongong. nsw.gov.au/council/publicdocuments/Pages/default. aspx

Bradbery, G. (2017b). Cultural. Retrieved March 10 $0^{\text {th }}, 2017$ from http://www.wollongong.nsw.gov.au/services/ artculture/Pages/default.aspx

Buntin, M. B., Burke, M. F., Hoaglin, M. C., \& Blumenthal, D. (2011). The benefits of health information technology: A review of the recent literature shows predominantly positive results. Health Affairs, 30.3(3), 464-471.

Galliers, R. D., \& Leidner, D. E. (2003). Strategic information management: Challenges and strategies in managing information systems. UK: ButterworthHeinemann.

Gamayanto, I. (2004). Porter s five forces model Scott Morton s five forces model Bakos Treacy model analyzes strategic information systems management. Jurnal Informatika, 5(2), 127-134. https://doi. org/10.5539/ijbm.v6n5p100

Gehl, J. (2014). A city for people. Retrieved April 12 $2^{\text {th }}$, 2017 from http://www.wollongong.nsw.gov.au/ development/planningforthefuture/Pages/default. aspx

Hussin, N. B., Othman, A. S., \& Jamaludin, A. (2017). Determinants of Strategic Information Management (SIM): A case study in a Malaysia Bank. Qualitative and Quantitative Methods in Libraries, 4(3), 679692.
Khan, W. (2016). Strategic Information Systems Planning (SISP) practices in health care sectors of Bangladesh. European Scientific Journal, 12(6), 307-321.

Land, W. L. A. (2016). Wagonga LALC 2014-2018 community, land and business plan. Retrieved June $10^{\text {th }}, 2017$ from https://wlalc.com.au/

Lin, C., Huang, Y. A., \& Cheng, M. S. (2007). The adoption of IS/IT investment evaluation and benefits realization methodologies in service organizations: IT maturity paths and framework. Contemporary Management Research, 3(2), 173-194.

Marabelli, M., \& Galliers, R. D. (2017). A reflection on information systems strategizing: The role of power and everyday practices. Information Systems Journal, 27(3), 347-366.

Omar, A., Bogabol, A., Musadieq, M. A. L., \& Handayani, S. R. (2014). The need for management information systems on strategic planning process in Libyan health service organizations. IOSR Journal of Bussines and Management (IOSR-JBM), X(X), 1326.

Peppard, J., Galliers, R. D., \& Thorogood, A. (2014). Information systems strategy as practice: Micro strategy and strategizing for IS. Journal of Strategic Information Systems, 23(1), 1-10.

Pratikna, R. N., \& Gamayanto, I. (2017). Developing leadership systems inside university using Jim Collins method [good to great]: People management development to face ASEAN economic community in Indonesia. Review of Integrative Business and Economics Research, 6(3), 45-55.

Sanson, L. (2015). Information Systems Strategic Plan 2015-2019. Retrieved June 12 $2^{\text {th }}, 2017$ from http:// www.doc.govt.nz/Documents/about-doc/policiesand-plans/information-systems-strategic-plan.pdf.

Ward, G. (2017). A city transformed. Retrieved August $8^{\text {th }}$, 2017 from http://www.wollongong.nsw.gov.au/city/ economicdevelopment/Pages/CityCentre.aspx

Wilkin, C. L., \& Cerpa, N. (2012). Strategic information systems planning: An empirical evaluation of its dimensions. Journal of Technology Management \& Innovation, 7(2), 52-62. 